Iranian Journal of Breast Diseases. 2021;14(3):4-11.
Original Article

\section{Comparison of Physician and Multidisciplinary Team's Opinions on the Diagnosis and Treatment of Women with Breast Diseases at Motamed Cancer Institute}

\author{
Bayatloo $A^{1}$, Golfam $F^{1}$, Haghighat $S^{2}$, Olfatbakhsh $A^{3^{*}}$ \\ ${ }^{1}$ Surgery Departement, Faculty of Medicine, Shahed University, Tehran, Iran \\ ${ }^{2}$ Quality of Life Department, Breast Cancer Research Center, Motamed Cancer \\ Institute, ACECR, Tehran, Iran \\ ${ }^{3}$ Breast Diseases Department, Breast Cancer Research Center, Motamed \\ Cancer Institute, ACECR, Tehran, Iran
}

Receive: $18 / 3 / 2021$

Accepted: 22/9/2021

"Corresponding Author: folfatbakhsh@yahoo.com

Ethics Approval: IR.SHAHED.REC.1399.037

\begin{abstract}
Introduction: Worldwide, breast cancer is the most common canceraffecting women. The complexity of decision-making in the diagnosis and treatment of patients highlights the necessity for a team approach, mostly multidisciplinary team (MDT). The aim of this study was to compare the opinions of the MDT and the physician on the diagnosis and treatment of women with breast diseases at Motamed Cancer Institute.
\end{abstract}

Methods: This cross-sectional study was performed on 122 women with breast symptoms. Patients were enrolled in the study in diagnostic and therapeutic groups. After introducing patients' complaints at the MDT meeting, each member expressed their suggestions and at the end of the meeting the final decision which was approved by the majority of members was acknowledged as the opinion of the MDT meeting. Then, the MDT decision was compared with the preliminary decision of the physician.

Results: The final decision of the MDT in the diagnostic group was the same as the physician in $48.9 \%$ of the cases, and the MDT changed the diagnosis in $51.1 \%$ of patients $(\mathrm{P}<0.001)$. In the treatment group, the final decision of the MDT was the same as the physician in $28.6 \%$ of cases and in $71.4 \%$, the MDT changed the treatment procedure $(\mathrm{P}<0.001)$.

Conclusion: Using an MDT approach in the management of breast diseases reduces the use of aggressive procedures, and helps the physician to make decisions precisely with more confidence in complicated cases.

Keywords: Multidisciplinary Team, Breast Cancer, Diagnosis, Treatment 


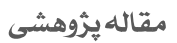
مقايسه نظر يزشك معالج با نظر تيم مولتى ديسييلينرى در مديريت تشخيص و درمان بيمارىهاى يستان در يخوهشكده سرطان معتمد

$$
\text { امير بياتلو'، فرزانه كَلفام'، شهير حقيقت '، آسيه الفت بخش بّ" }
$$

اكروه جراحي، دانشكده يزشكى، دانشكاه شاهد، تهران، ايران

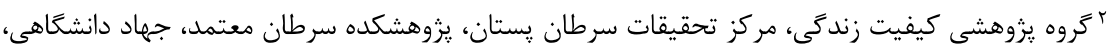
تمهران، ايران

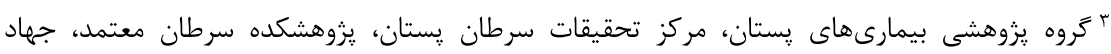
دانشعاهى، تهران، ايران
فصلنامه بيمارى هاى بستان ايران

$|\varepsilon \cdot \cdots !| \varepsilon(r): \varepsilon-11$

\section{OUt?}

مقدمه: سرطان بستان شايعترين سرطان زنان در دنياست. پِيشرفتهاى روزافزون در زمينه

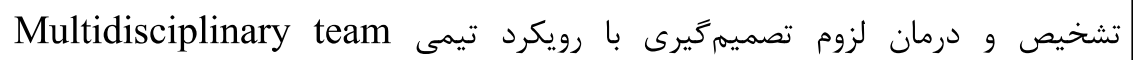

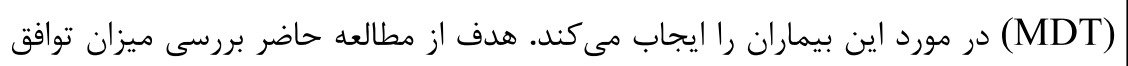

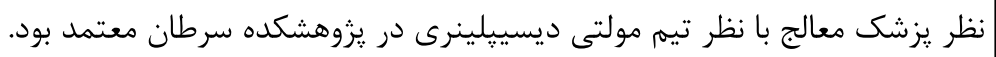
روش بررسى: اين مطالعه مقطعى، توصيفى و تحليلى روى rآ آزن مراجعه كننده با علايم

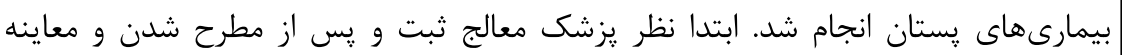

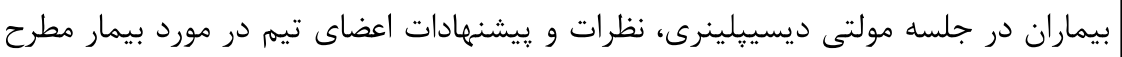

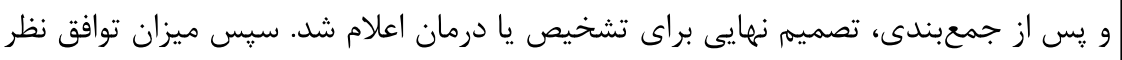

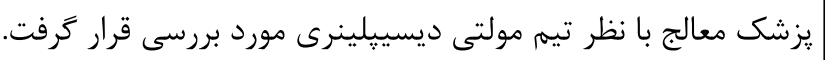

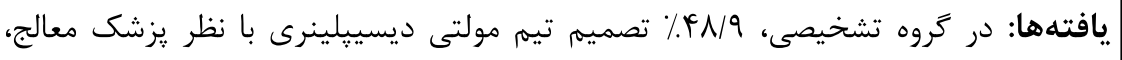

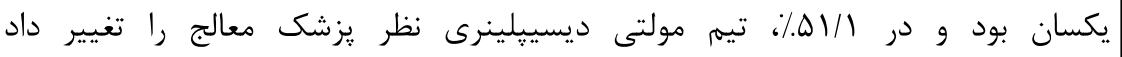

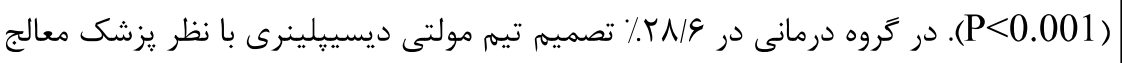

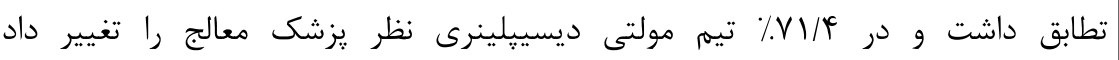
. $(\mathrm{P}<0.001)$

نتيجهَيرى: استفاده از رويكرد مولتى ديسييلينرى در تشخيص و درمان سرطان پستان

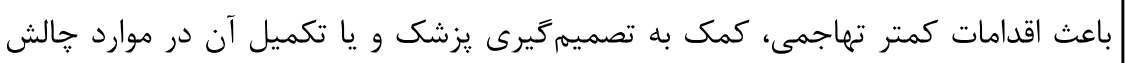
برانكَيز مىشود. |وازههاى كليدى: سرطان پِّتان، تيم مولتى ديسييلينرى، تشخيص، درمان

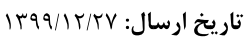

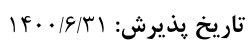

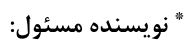
folfatbakhsh@yahoo.com 
سرطان ريستان متشكل از جراح، انكولوزيست،

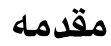

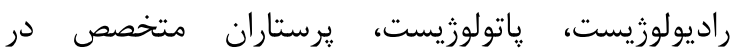
زمينههاى مختلف مثل شيمىدرمانى و...، راديولوزيست و جراح يلاستيك مىباشند و تعداد اين افراد در كروههاى مختلف متفاوت است (9).

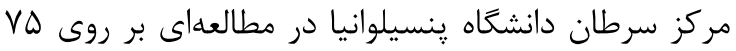

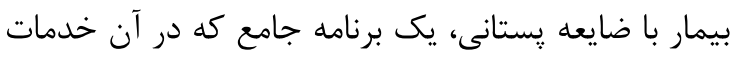

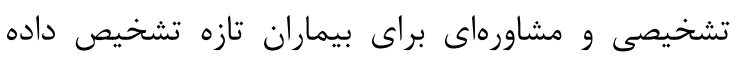
شده در يك جلسه MDT فراهم مىشد، ارائه كردند. اين

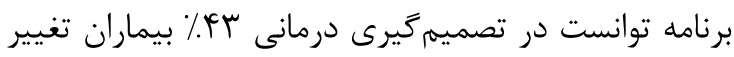

ايجاد كند (•) (1).

Chang-Hung Tsai

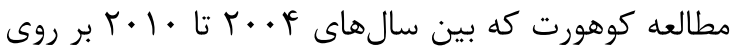

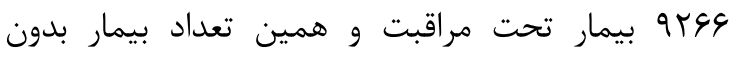

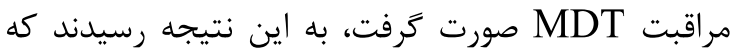
خطر نسبى عود و مرك براى بيماران مبتلا به سرطان

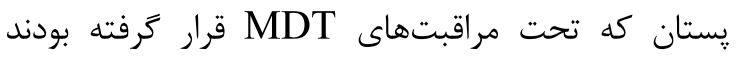

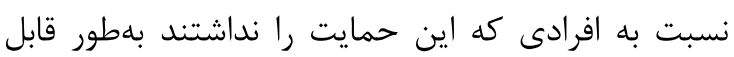

$$
\text { توجهى كمتر بود (ه (1). }
$$

و همكاران در سال 19 • Tianlong Lu

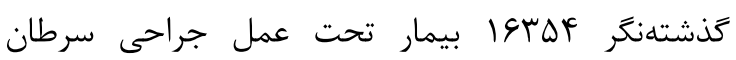

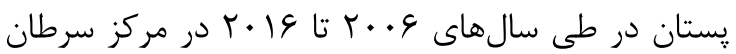

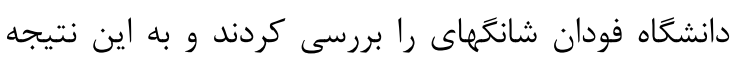

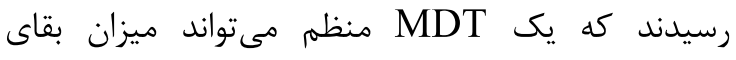

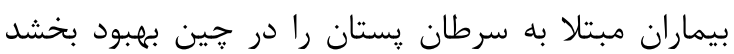

جلسات MDT در مراكز علمى به دو شكل بركزار

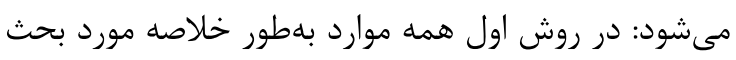
قرار مى گيرند و در روش دوم فقط موارد خاص يیيجيده اما بلهور مفصل مورد بحث قرار مى كيرند (N). امروزه

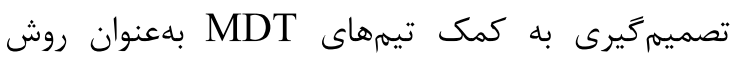
استاندارد طلايى مراقبتهاى سرطان در سيستم سلامت

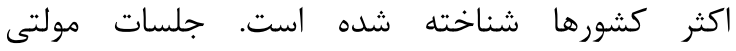

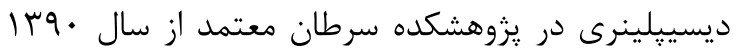

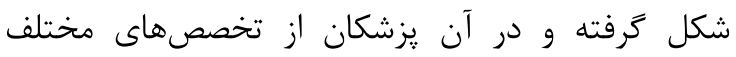

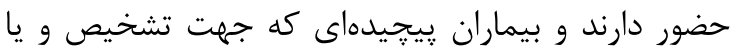
درمان نياز به تصميمَيرى گروهى دارند، در اين جلسات

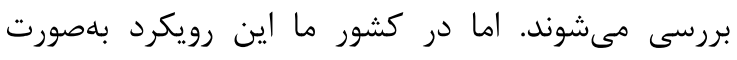

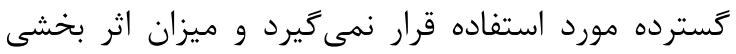

سرطان پِتان شايعترين سرطانى است كه زنان را در

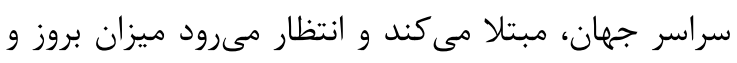

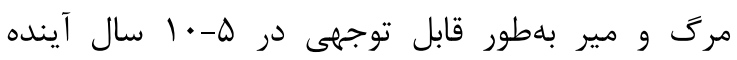

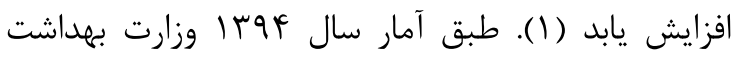

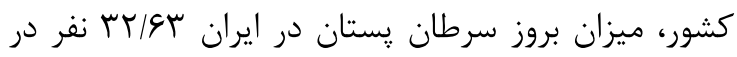

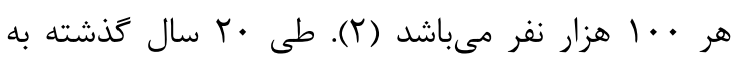
دليل افزايش دانش در مورد خواص بيولوزيك و تغييرات

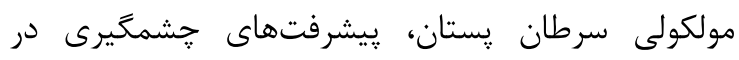

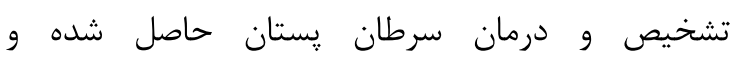

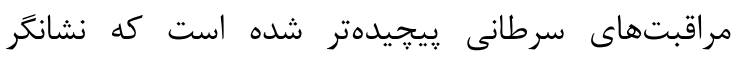

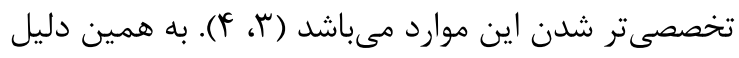

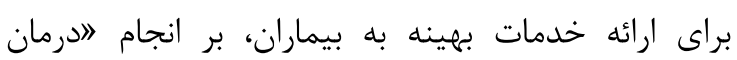

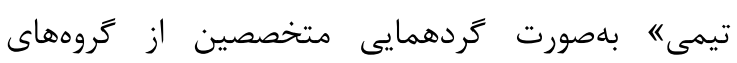
مختلف تاكيد مىشود. نمونهاى از اين كار كروهى، تشكيل مترديل تيمهاى مولتى ديسييلينرى ( Multidisciplinary

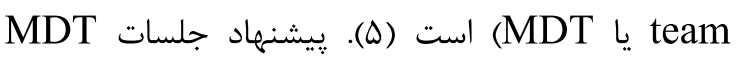
اولين بار در سال ه99 199 در بخش سلامت بيمارستان كلاسكو مطرح شد (؟). طبق تعريف بخش سلامت لندن،

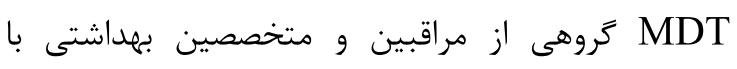

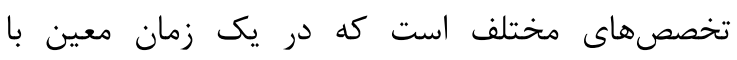

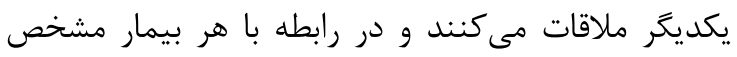

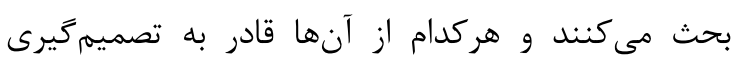

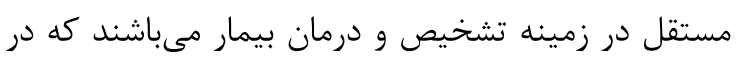

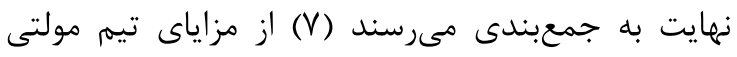

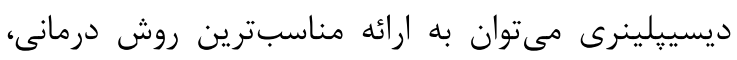

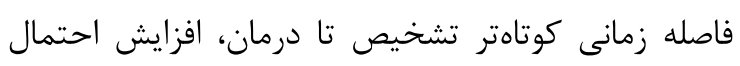

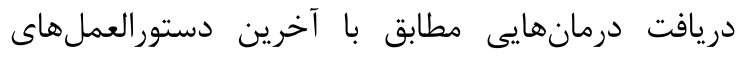

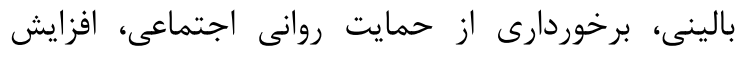

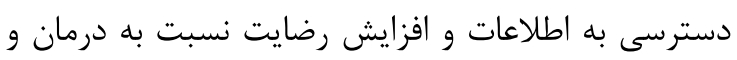

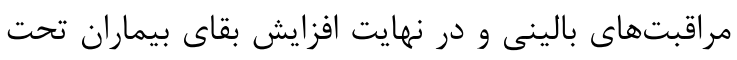

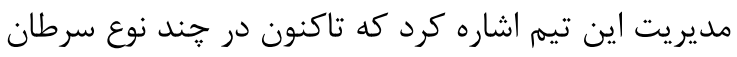

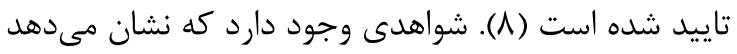
تصميماتى كه از سوى MDT مطرح مىشود، بيشتر از

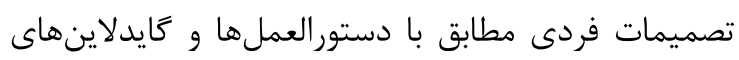

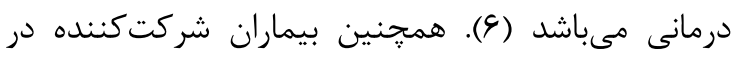

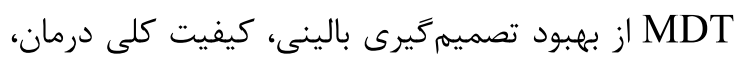

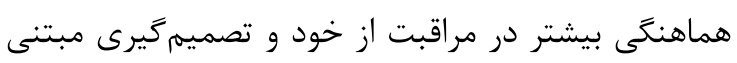

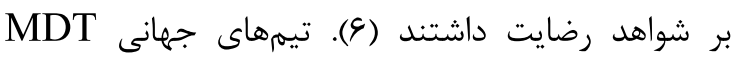


تكميل روش درمانى: وقتى MDT اقدامى اضافهتر از نظر

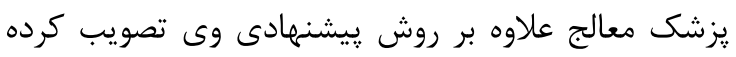

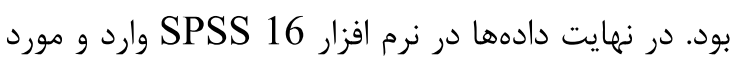
تجزيه و تحليل قرار گرفتند. يزوهش حاضر در كميته اخلاق دانشگاه شاهد با كد IR.SHAHED.REC.1399.037 ثبت شده است.

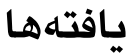

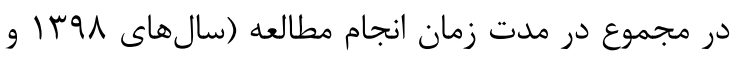

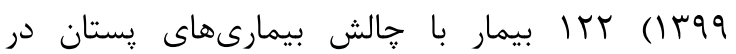
جلسات MDT يزوهشكده سرطان معتمد معرفى شدند.

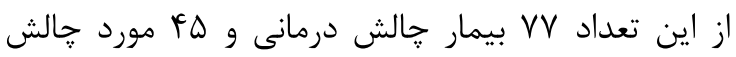
تشخيصى داشتند.ميانگين سنى بيماران

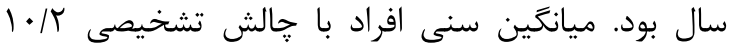
سن F F/A

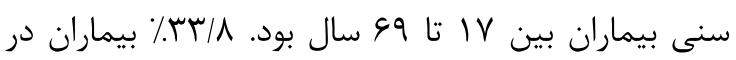

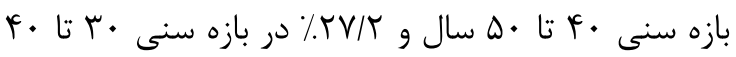
سال بودند كه اكثريت افراد حاضر در مطالعه را تشكيل

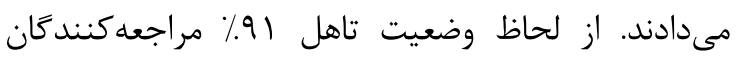
متاهل و 9\% آنها مجرد بودند. فراوانى و مشخصات بيمارانى كه جهت تعيين تكليف روش تشخيصى در جلسه

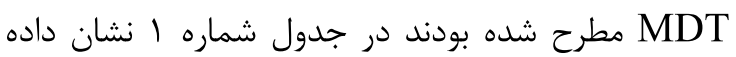
شده است. همان كونه كه مشاهده مىشود نظر يزشك كه در ستون اول آمده است در جلسه MDT تاييد و يا با منان ي يشنهادهاى ديكرى جايكزين شده است.

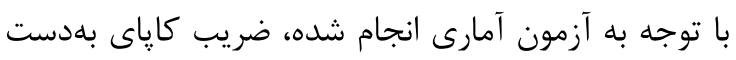

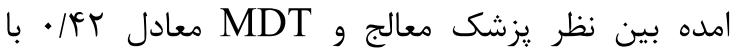

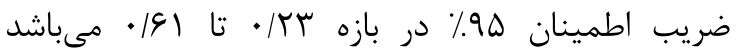

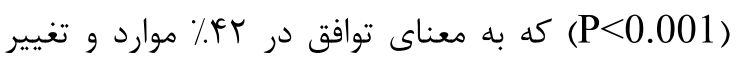

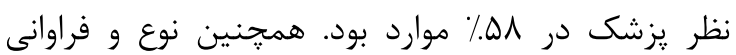
تاثير MDT بر تشخيص بيماران در جدول شماره r نشان

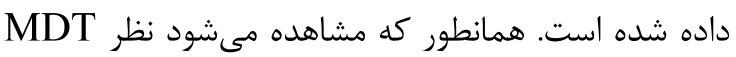

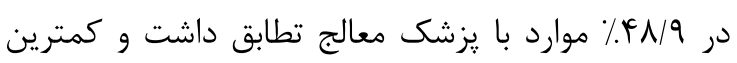
فراوانى مربوط به مواردى است كه اقدام تهاجمىترى توسط MDT بيشنهاد شد. فراوانى و مشخصات بيمارانى كه جهت تعيين تكليف روش درمانى در جلسه مطرح شده بودند در جدول شماره r نشان داده شده دران
تيمهاى MDT بررسى نشده است. هدف از مطالعه حاضر بررسى ميزان توافق نظر يزشك معالج با نظر MDT درس ندره ي تروهشكده سرطان معتمد بود.

\section{مواد و روشها}

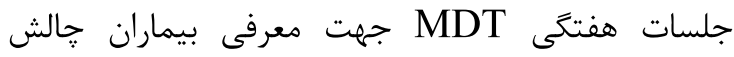

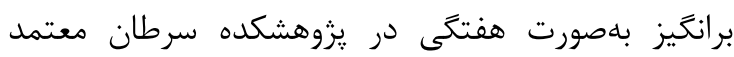

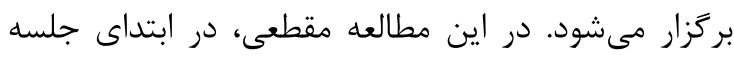

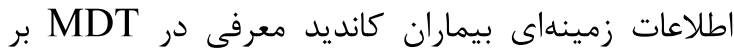

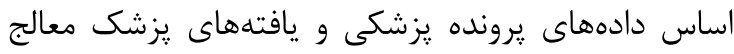

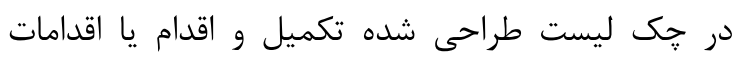
ييشنهادى يزشك معالج در مورد تشخيص يا درمان ثبت ندان

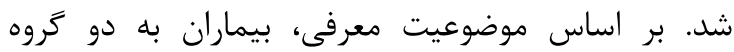

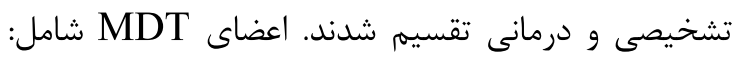

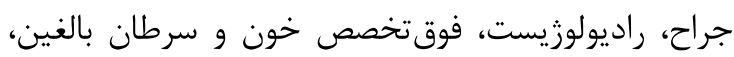

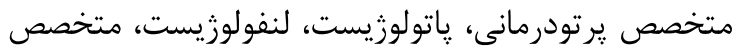
زنتيك، متخصص تغذيه و برستار كلينيك ييخيرى بودند.

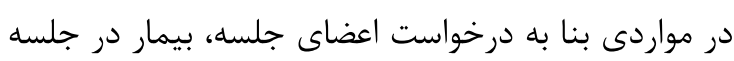

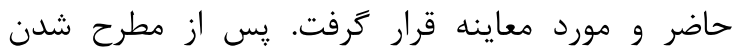

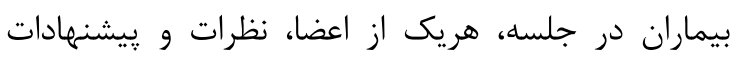

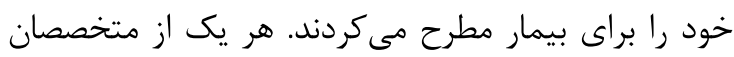

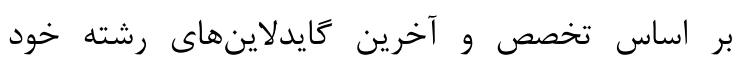
نظرات خود را مطرح و در انتهاى جلسه يك جمعبندى

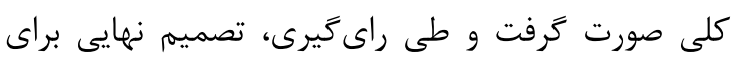

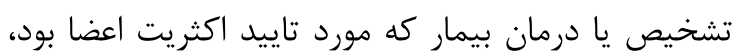
بهنوان نظر جلسه MDT ثبت شد. بئمار تغيير در نظر يزشك معالج بلهصورت اقدام تهاجمىتر يا نهان

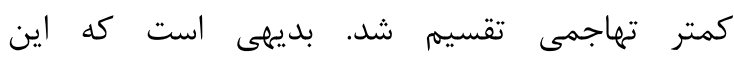
تقسيمبندى بر اساس جالش تشخيصى يا درمانى متفاوت

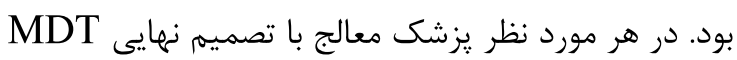

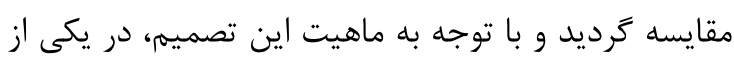
اين كروههاى زير قرار كرفت. اقدام كمتر تهاجمى: انجام روش تشخيصى يا درمانى كه با كرفي

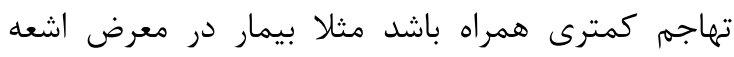

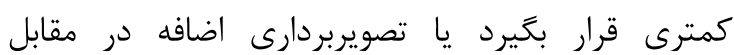
نمونهبردارى سوزنى.

اقدام تهاجمىتر: بر عكس موارد فوق. تعيين روش تشخيصى يا درمانى: وقتى يز ئكى معالج انتخابى نداشته و آن را به نظر MDT موكول كرده بود. 
كه MDT روش اضافهترى را به يزشك معالج بيشنهاد كرد كه تحت عنوان تكميل درمان تقسيمبندى شده است.

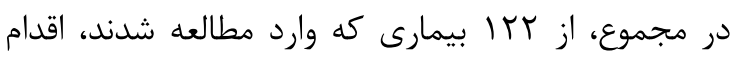

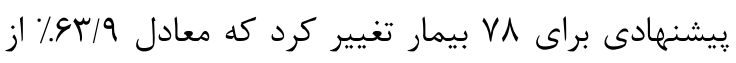

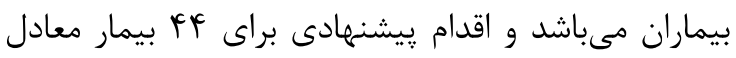

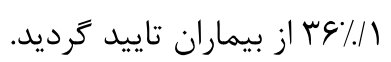

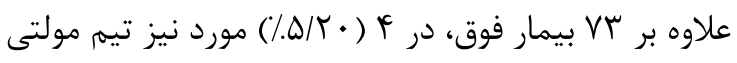

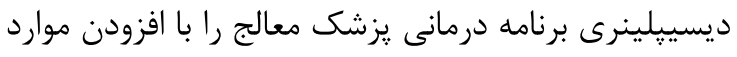

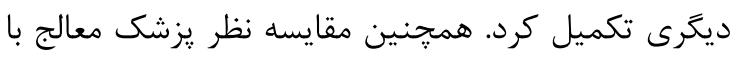

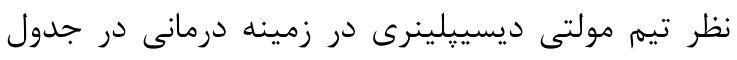

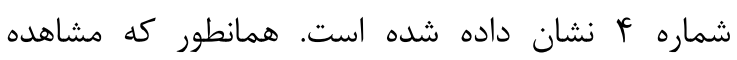

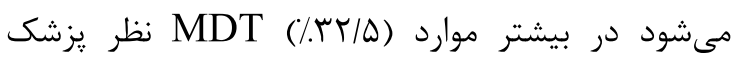

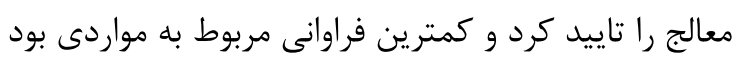

جدول ا: توزيع فراوانى اقدامات تشخيصى بيشنهادى بزشكان و MDT

\begin{tabular}{|c|c|c|c|c|c|c|}
\hline باتولوزى بينى & اكسيزيون & كو بيكيرى مدت & بيويسى تحت كايد & MRI & مجموع بيماران & MD \\
\hline . & 1 & 1 & 1 & r & v & MRI \\
\hline · & · & 1 & $\Delta$ & . & 4 & بيويسى تحت كايد سونوكرافى \\
\hline • & 1 & $\Delta$ & · & - & 4 & ييخيرى كوتاه مدت \\
\hline 1 & $\checkmark$ & f & 1 & 1 & If & اكسيزيون ضايعه \\
\hline · & 1 & 1 & 1 & · & r & بيويسى با وكيوم \\
\hline 1 & 1 & 1 & · & · & r & بازبينى ياتولوزى \\
\hline · & r & r & r & • & 4 & بدون نظر \\
\hline r & ir & 10 & 1. & $\Delta$ & FD & كل \\
\hline
\end{tabular}

\begin{tabular}{|c|c|c|}
\hline درصد فراوانى & 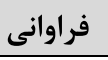 & تاثير MDT بر توصيه تشخيصى بزشك \\
\hline FN/q & tr & روند تشخيص را تاييد كرد \\
\hline re/V & it & اقدام تشخيصى كمتر تهاجمى را يِيشنهاد كرد \\
\hline $11 / 1$ & $\Delta$ & اقدام تشخيصى تهاجمى ترى را بيشنههاد كرد \\
\hline $1 \pi / r$ & 4 & روند تشخيص را تعيين كرد \\
\hline $1 \cdots$ & Fa & كل \\
\hline
\end{tabular}

جدول r: توزيع فراوانى اقدامات درمانى ييشنهادى يزشكان و MDT

\begin{tabular}{|c|c|c|c|c|c|c|c|c|c|}
\hline تشخيصى & كوتاه مدت & شيمى درمانى & راديوترابى & بردارى & غديس لنفاويون & $\begin{array}{c}\text { ماستكتومى مديفيه } \\
\text { راديكيه }\end{array}$ & جفظ هستان & 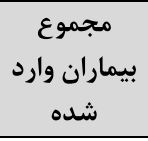 & MDT تصميم \\
\hline 1 & f & $\Delta$ & · & $\cdot$ & 1 & 1 & $r$ & 10 & جراحى حفظ يستان \\
\hline - & 1 & . & - & 1 & . & $\Delta$ & 1 & $\wedge$ & مديفيه ماستومى راديكال \\
\hline - & . & 1 & - & - & - & - & - & 1 & لنفاوى زير بغل غديون \\
\hline . & r & r & . & $\mathrm{v}$ & 1 & 1 & 1 & If & نمونهبر دارى \\
\hline · & $\cdot$ & $\cdot$ & r & - & · & · & · & r & راديوترايى \\
\hline - & $\Delta$ & r & . & 1 & . & r & r & if & شيمىدرمانى \\
\hline - & 1 & - & - & 1 & - & . & r & f & بييَيرى كوتاه مدت \\
\hline - & f & $r$ & - & f & · & 1 & f & 10 & بدون نظر \\
\hline 1 & IV & 14 & r & if & r & 1. & $\pi$ & vr & كل \\
\hline
\end{tabular}




\begin{tabular}{|c|c|c|}
\hline درصد فراوانى & فراوانى & تاثير MDT بر توصيه درمانى يزشك \\
\hline$r T / \Delta$ & rt & روند درمان را تاييد كرد \\
\hline$r \cdot 1 \mathrm{~A}$ & 19 & درمان كمتر تهاجمى را بيشنهاد كرد \\
\hline$V / \Lambda$ & 9 & درمان تهاجمى ترى را بيشنهاد كرد \\
\hline $19 / \Delta$ & 10 & روند درمان را تعيين كرد \\
\hline $19 / 9$ & If & روند درمان را تغيير داد \\
\hline$r / \Delta$ & r & روند درمان را تكميل كرد \\
\hline $1 .$. & VV & كل \\
\hline
\end{tabular}

براى MDT ب/ از بيماران اقدامات تشخيصى كمتر

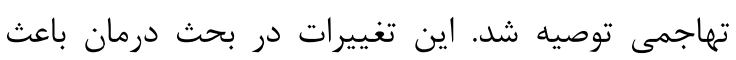

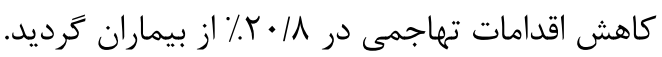
با توجه به گستردكى شرايط بالينى بيماران ممكن است آدان

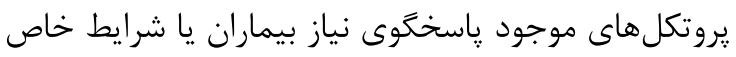

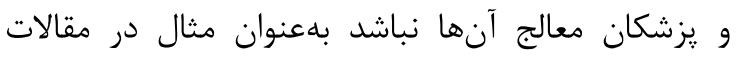

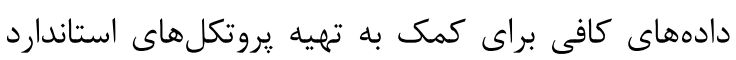

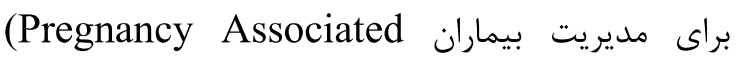
Breast Cancer) PABC باردار توسط يك تيم جند رشتهاى بيخيرى شوند و در هر

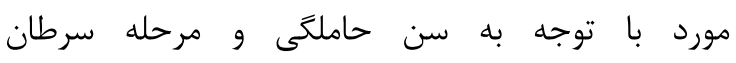

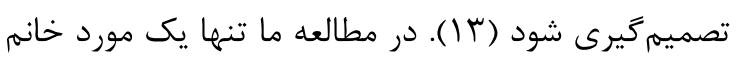

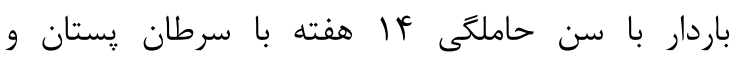
آسيبشناسى مشابه وجود داشت كه بز باردى مار معالج مشابه

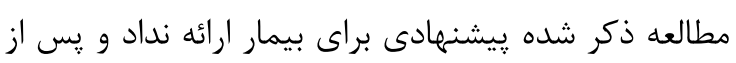

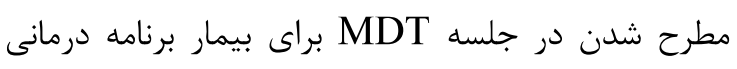
تعيين گرديد. به علاوه خطر نسبى عود و مرى برديد براى بيماران مبتلا به

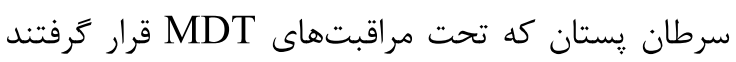
نسبت به افرادى كه اين كار را انجام ندادند در مطالعات

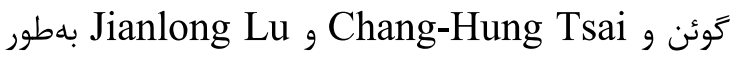

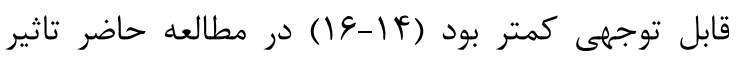
بر روند تشخيصى و درمانى بيماران تاييد شد.

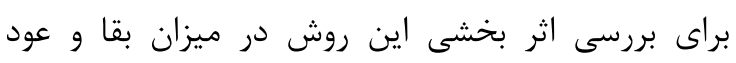

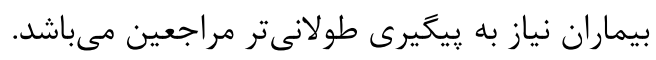

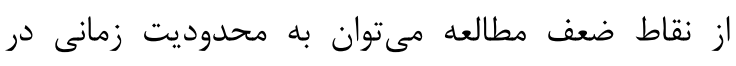

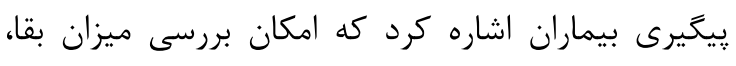
عود و مرى مير را از محققين سلب كرد. همجنين ئنين

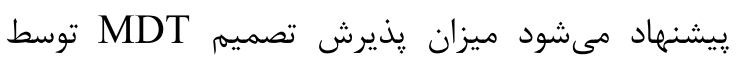

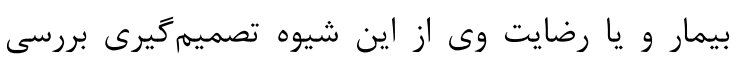

اين مطالعه نشان داد كه استفاده از رويكرد تيمى و شركت

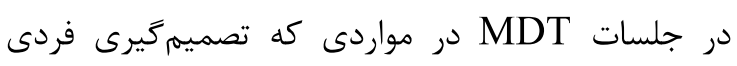
دشوار است، بهطور موثرى باعث تغيير در نظرات اوليه

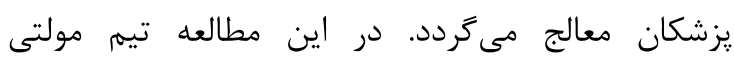

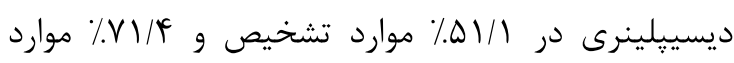

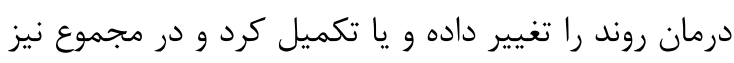

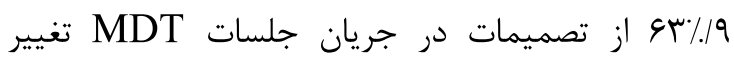

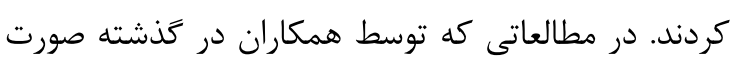

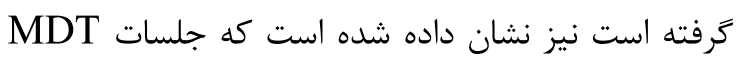
توانست در تصميم گيرى درمانى بيماران تغيير ايجاد كند ندان

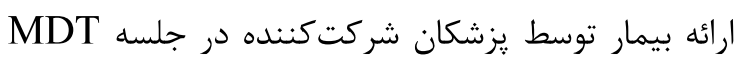

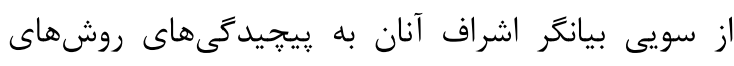

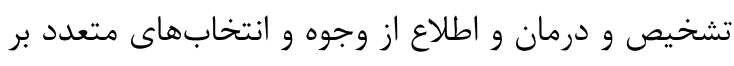

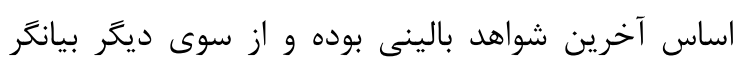
روحيه آكادميك و نقديذير يزشك معالج بوده كه نهايتا

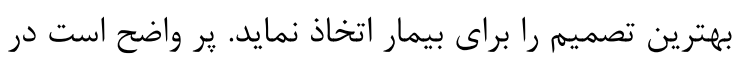

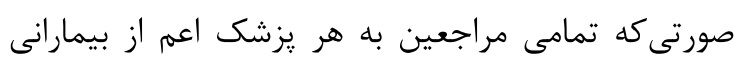

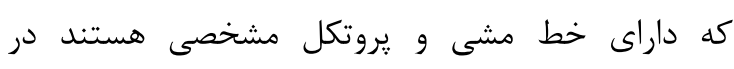
جلسات MDT مطرح شوند، اين اختلاف بهطرز قابل ملاحظهاى كاهش خواهد يافت.

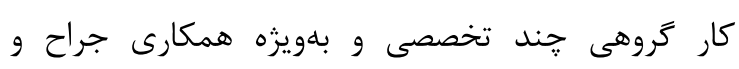
راديولوزيست مداخله بىمورد، در عين افزايش دقت تشخيص، ميزان اقدام

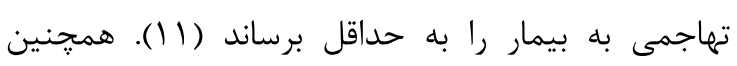

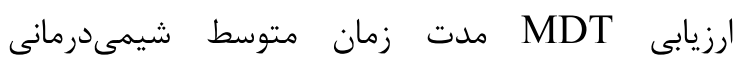

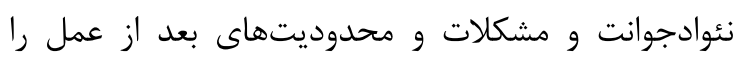

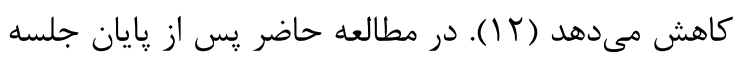




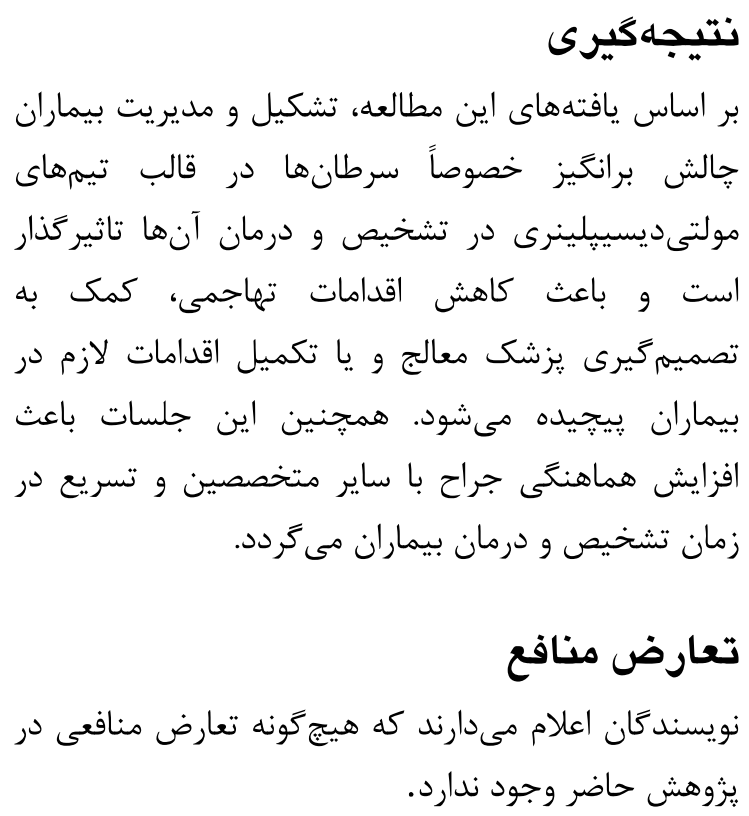

\section{References}

1. Anastasiadi $\mathrm{Z}$, Lianos $\mathrm{G}$ Ignatiadou $\mathrm{E}$, Harissis HV, Mitsis M. Breast cancer in young women: an overview. 2017; 69(3): 3137.

2. Ministry of health and medical education, non-communicable disease management center, Cancer office. National Cancer Registration Program Report, Iran, Tehran: Mirmah; 2019.

3. Taylor C, Shewbridge A, Harris J, Green JS. Benefts of multidisciplinary teamwork in the management of breast cancer. Breast Cancer: Targets and Therapy. 2013; 5:79-85.

4. Mukherjee, S. The Emperor of all Maladies: A Biography of Cancer, London, Fourth Estate. New York: SCRIBNER. 2011.

5. West MA, Lyubovnikova J. Illusions of team working in health care. J Health Organ Manag. 2013; 27:134-42.

6. Saini KS. Taylor C. Ramirez AJ. Palmieri C, Gunnarsson U, Schmoll HJ. Role of the multidisciplinary team in breast cancer management: results from a large international survey involving 39 countries. Annals of Oncology. 2012; 23(4): 853-9.

7. National Cancer Peer Review-National Cancer Action Team. Manual for Cancer Services: Service User Partnership Group Measures. London. 2011.

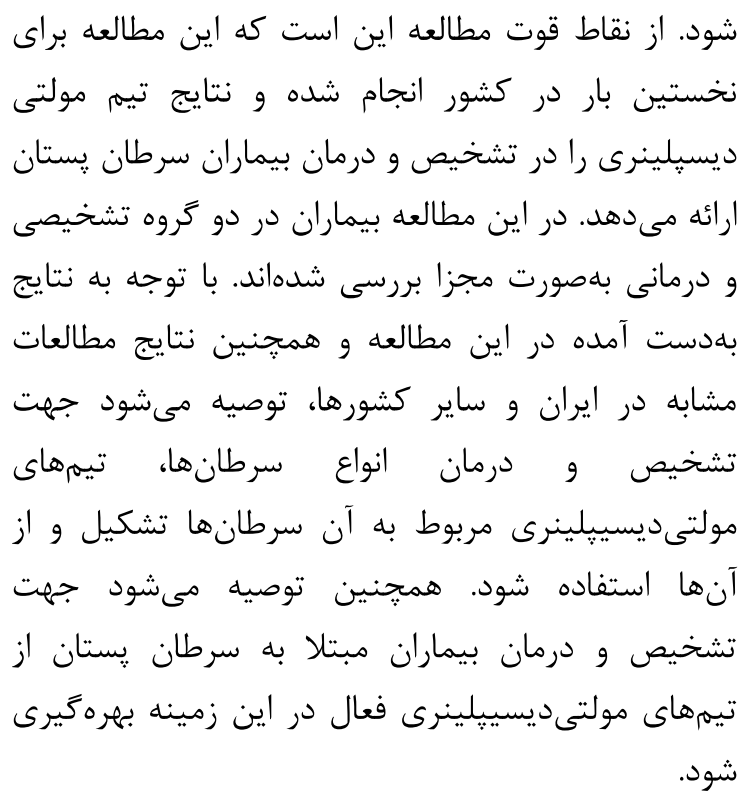

8. El-Saghir NS, Keating NL, Carlson RW, Khoury KE, Fallowfield L. Tumor boards: optimizing the structure and improving efficiency of multidisciplinary management of patients with cancer worldwide. Am Soc Clin Oncol Educ Book. 2014; 34:e461-6.

9. Jenkins VA, Fallowfield L, Poole K. Are members of multidisciplinary teams in breast cancer aware of each other's informational roles?. Quality in Health Care. 2001;10:70-5.

10. Chang JH, Vines E, Bertsch H, Czerniecki BJ, Fraker DL, Rosato EF, et al. The impact of a multidisciplinary breast cancer center on recommendations for patient management; The university of pennsylvania experience. American Cancer Society. 2001; 1231-7.

11. Jolaei A, Kalantari M. Histological diagnosis of breast lesions by thick needle biopsy: A key point in the new strategy for the diagnosis and treatment of breast cancer and the basic principle in respecting patient rights. Iranian Journal of Surgery. 2010; 18(2): 39-49.

12. Basso M, Corallo S, Calegari M, Zurlo IV. The impact of multidisciplinary team management on outcome of hepatic resection in liver-limited colorectal metastases. Scientific Reports nature research. 2020; 10 : 10871. 
13. Mohamadianamiri M, Aklamli M, Shojaei F. Diagnosis and management of metastatic breast cancer during pregnancy by a multidisciplinary team: A case report. Archives of breast cancer. 2019; 6(2): 96-99.

14. Gwen A, Eileen K. Effects of multidisciplinary team working on breast cancer survival: retrospective, comparative, interventional cohort study of 13722 women. BMJ. 2012; 344:1-9.
15. Tsai Ch.H, Hsieh H, Lai $T$ et al. Effect of multidisciplinary team care on the risk of recurrence in breast cancer patients: A national matched cohort study. The Breast. 2020; 53: 68-76.

16. Lu J, Jiang Y, Qian $M$ et al. The improved effects of a multidisciplinary team on the survival of breast cancer patients: experiences from china. International Journal of environmental research and public health. 2020; 17(1):277. 